\title{
Biomechanical Loading Modulates Proinflammatory and Bone Resorptive Mediators in Bacterial-Stimulated PDL Cells
}

\author{
Andressa Vilas Boas Nogueira, ${ }^{1,2}$ Marjan Nokhbehsaim, ${ }^{2,3}$ Sigrun Eick, ${ }^{4}$ \\ Christoph Bourauel, ${ }^{3,5}$ Andreas Jäger, ${ }^{3,6}$ Søren Jepsen, ${ }^{3,7}$ Carlos Rossa Jr., ${ }^{1}$ \\ James Deschner, ${ }^{2,3}$ and Joni Augusto Cirelli ${ }^{1}$ \\ ${ }^{1}$ Department of Diagnosis and Surgery, School of Dentistry at Araraquara, Univ Estadual Paulista (UNESP), \\ 14801-903 Araraquara, SP, Brazil \\ ${ }^{2}$ Section of Experimental Dento-Maxillo-Facial Medicine, Center of Dento-Maxillo-Facial Medicine, University of Bonn, \\ 53111 Bonn, Germany \\ ${ }^{3}$ Clinical Research Unit 208, Center of Dento-Maxillo-Facial Medicine, University of Bonn, 53111 Bonn, Germany \\ ${ }^{4}$ Department of Periodontology, Oral Microbiology, University of Bern, 3010 Bern, Switzerland \\ ${ }^{5}$ Oral Technology, Center of Dento-Maxillo-Facial Medicine, University of Bonn, 53111 Bonn, Germany \\ ${ }^{6}$ Department of Orthodontics, Center of Dento-Maxillo-Facial Medicine, University of Bonn, 53111 Bonn, Germany \\ ${ }^{7}$ Department of Periodontology, Operative and Preventive Dentistry, Center of Dento-Maxillo-Facial Medicine, \\ University of Bonn, 53111 Bonn, Germany
}

Correspondence should be addressed to Joni Augusto Cirelli; cirelli@foar.unesp.br

Received 31 January 2014; Revised 26 April 2014; Accepted 29 April 2014; Published 25 May 2014

Academic Editor: Hermann Gram

Copyright (c) 2014 Andressa Vilas Boas Nogueira et al. This is an open access article distributed under the Creative Commons Attribution License, which permits unrestricted use, distribution, and reproduction in any medium, provided the original work is properly cited.

\begin{abstract}
The present study aimed to evaluate in vitro whether biomechanical loading modulates proinflammatory and bone remodeling mediators production by periodontal ligament (PDL) cells in the presence of bacterial challenge. Cells were seeded on BioFlex culture plates and exposed to Fusobacterium nucleatum ATCC 25586 and/or cyclic tensile strain (CTS) of low (CTSL) and high (CTSH) magnitudes for 1 and 3 days. Synthesis of cyclooxygenase-2 (COX2) and prostaglandin E2 (PGE2) was evaluated by ELISA. Gene expression and protein secretion of osteoprotegerin (OPG) and receptor activator of nuclear factor kappa-B ligand (RANKL) were evaluated by quantitative RT-PCR and ELISA, respectively. F. nucleatum increased the production of COX2 and PGE2, which was further increased by CTS. F. nucleatum-induced increase of PGE2 synthesis was significantly $(P<0.05)$ increased when CTSH was applied at 1 and 3 days. In addition, CTSH inhibited the F. nucleatum-induced upregulation of OPG at 1 and 3 days, thereby increasing the RANKL/OPG ratio. OPG and RANKL mRNA results correlated with the protein results. In summary, our findings provide original evidence that CTS can enhance bacterial-induced syntheses of molecules associated with inflammation and bone resorption by PDL cells. Therefore, biomechanical, such as orthodontic or occlusal, loading may enhance the bacterial-induced inflammation and destruction in periodontitis.
\end{abstract}

\section{Introduction}

Periodontitis is characterized by a pathological process triggered by the host response against pathogenic bacteria present in the dental biofilm. It is a chronic inflammatory disease that affects the periodontium resulting in tissue destruction and even in the loss of the dental organ [1]. Host immune response against this infection leads to the production of inflammatory mediators. Cytokines such as interleukin- $1 \beta$ and tumor necrosis factor- $\alpha$ are the primary mediators responsible for stimulating the production of secondary mediators like chemokines and cyclooxygenases (COX) [2]. These inflammatory molecules activate osteoclasts and induce bone resorption as a result of an exacerbated host 
response. Thus, understanding the regulation of proinflammatory mediators and their effects in periodontal tissues has been the objective of many studies [2-6].

Besides pathological conditions, orthodontic tooth movement also stimulates those biological mediators in response to therapeutic mechanical forces. Tooth displacement occurs as a result of periodontal tissues remodeling process, which is predominantly characterized by bone resorption and bone formation on pressure and tension sides, respectively. PDL cells are constantly subjected to several types of mechanical forces, such as compression, tension, and shear stress. In addition, they are considered as mechanoresponsive cells that mediate the response of the connective tissue to mechanical loading [7]. During orthodontic movement, several proinflammatory mediators are synthesized and released, especially cytokines and prostaglandins, playing an important role in bone remodeling. However, these molecules may also interfere with the underlying disease bacterial-induced inflammatory process and exacerbate periodontitis [8]. Although some studies [8-10] have been conducted to understand the effects of concomitant periodontal disease and orthodontic movement on periodontal tissues, the interactions between periodontitis and biomechanical loading are as yet not well established.

Among the many molecules involved in the inflammatory process, COX is highly expressed during both periodontal disease and orthodontic tooth movement. After several types of stimuli, the membrane phospholipids of some cells release arachidonic acid, which is catalyzed by COX into prostanoids like prostaglandins and thromboxane. Two isoforms of COX are described, COX1 and COX2. COX1 is constitutively expressed in many tissues and is required to maintain organ and tissue homeostasis. In contrast, COX2 expression is induced by proinflammatory cytokines and lipopolysaccharide. COX2 is responsible for prostaglandin E2 (PGE2) production [11], which has an important role in the pathogenesis of periodontal diseases. High levels of PGE2 are detected in the gingiva and gingival crevicular fluid of patients with periodontal disease [12-15], acting as inflammatory mediator. Also, PGE2 has been associated with bone resorption during the progression of periodontal diseases $[14,16]$ by stimulating and activating osteoclast production [17] and by upregulating receptor activator of nuclear factor kappa-B (RANK) ligand (RANKL) expression [18]. Moreover, blocking endogenous PGE2 production with indomethacin has been shown to significantly inhibit the increase of osteoclasts by LPS-induced COX2 [19]. In addition to the role in the disease process, some studies have demonstrated high expression of COX2 and/or PGE2 in periodontal ligament (PDL) cells after in vitro mechanical loading [20-25] and high PGE2 level in gingival crevicular fluid during orthodontic movement at both compression and tension sides [26], suggesting its participation in bone remodeling process [7]. This role of PGE2 in bone remodeling can be confirmed due to the increase in orthodontic tooth movement achieved after PGE2 administration [27-30]. Furthermore, COX2/PGE2 were demonstrated to be responsible for RANKL upregulation in PDL cells under mechanical stress in vitro [21].

RANKL is a key molecule in osteoclast differentiation and activation. Increased level of this molecule is detected in periodontal disease and orthodontic tooth movement [21,31]. RANKL effects are counteracted by osteoprotegerin (OPG) and the balance between them regulates bone resorption [32]. The level of OPG in periodontitis seems to be lower when compared to that in healthy patients [31], but OPG regulation during mechanical stress is still uncertain [33, 34]. Some reports suggest that OPG expression remains unchanged while other reports suggest that its expression is upregulated in PDL cells subjected to biomechanical loading [21, 34, 35]. The fact is that RANKL and OPG are involved in PDL and bone remodeling.

However, no previous study has evaluated the expression of those important molecules COX2/PGE2 and RANKL/ OPG when both conditions, bacterial challenge and mechanical force, are concomitantly present. Thus, the aim of the present study was to evaluate in vitro whether biomechanical loading modulates bacterial regulation of proinflammatory and bone remodeling mediators in PDL cells.

\section{Materials and Methods}

2.1. Cell Culture. The experiment was approved by the Ethics Committee of the University of Bonn and informed parental consent was obtained. Human periodontal ligament (hPDL) fibroblasts were used. Cells were obtained from six periodontally healthy donors, who underwent tooth extraction for orthodontic reasons. Cells were derived from the middle third of the tooth roots and maintained in DMEM (Dulbecco's Modified Eagle's Medium, Invitrogen, Karlsruhe, Germany) supplemented with 10\% FBS (fetal bovine serum, Invitrogen), 100 units of penicillin, and $100 \mu \mathrm{g} / \mathrm{mL}$ of streptomycin (Biochrom, Berlin, Germany) at $37^{\circ} \mathrm{C}$ in a humidified atmosphere of $5 \% \mathrm{CO}_{2}$. Cells were seeded between passages 3-5 $\left(1 \times 10^{5}\right.$ cells/well $)$ on 6-well BioFlex collagencoated culture plates (Flexcell International, Hillsborough, NC, USA) and grown to $80 \%$ confluence. FBS concentration was reduced to $1 \% 24$ hours prior to experiments in order to avoid interference from its components and to synchronize the cell cycle.

2.2. Cell Stimulation. Cells were stimulated with the inactivated oral pathogen Fusobacterium nucleatum ATCC 25586 $\left(\mathrm{OD}_{660 \mathrm{~nm}}: 0.025,0.05\right.$, and 0.1$)$ in order to mimic cellmicrobial interactions in vitro. In an anaerobic atmosphere, bacteria strain was precultivated for 48 hours on Schaedler Agar plates (Oxoid, Basingstoke, United Kingdom). Subsequently, bacteria were suspended in $\mathrm{PBS}\left(\mathrm{OD}_{660 \mathrm{~nm}}=1\right.$, equivalent to $1.2 \times 10^{9}$ bacterial cells $/ \mathrm{mL}$ ) and subjected twice to ultrasonication ( $160 \mathrm{~W}$ for $15 \mathrm{~min}$ ). Different OD concentrations were used in the first experiment to evaluate the dose response of PDL cells stimulated with $F$. nucleatum ATCC 25586. Afterwards, the lowest concentration capable of upregulating COX2 was chosen (OD 0.025) and used in the subsequent experiments. As in previous experiments, a strain device (CESTRA) developed at the University of Bonn 
was used to apply biomechanical forces to cells [36-38]. In addition to bacterial challenge, biomechanical forces were simulated by the application of cyclic tensile strain (CTS) of low (CTSL, 3\%) and high (CTSH, 20\%) magnitudes at a rate of $0.05 \mathrm{~Hz}$. PDL fibroblasts were exposed to F. nucleatum ATCC 25586, to CTS, and to their combinations for 1 day and 3 days. Moreover, cells were stimulated with F. nucleatum ATCC 25586 in the presence and absence of $10 \mu \mathrm{g} / \mathrm{mL}$ blocking antibodies against TLR2 (mouse anti-human TLR2 mAb TL2.1, 16-9917-82, eBioscience, San Diego, CA, USA) and TLR4 (mouse anti-human TLR4 HTA125, 16-9917-82, eBioscience) for 1 day. Cell viability of treated and control cells was $>95 \%$.

2.3. Quantitative RT-PCR. Total RNA extraction was performed using RNeasy Mini Kit (Qiagen, Hilden, Germany) according to manufacturer's protocol. RNA concentration was determined by NanoDrop ND-1000 (Thermo Fisher Scientific, Wilmington, DE, USA) spectrophotometer. $500 \mathrm{ng}$ of total RNA was reversely transcribed using the iScript Select cDNA Synthesis Kit (Bio-Rad, Munich, Germany) at $42^{\circ} \mathrm{C}$ for $90 \mathrm{~min}$ followed by $85^{\circ} \mathrm{C}$ for $5 \mathrm{~min}$, following manufacturer's instructions. Using the iCycler iQ detection system (Bio-Rad), SYBR Green (Qiagen), and specific primers (QuantiTect Primer Assay, Qiagen), gene expression of glyceraldehyde-3-phosphate dehydrogenase (GAPDH), COX2, OPG, and RANKL was evaluated by quantitative RTPCR. One microliter of cDNA was amplified as a template in a $25 \mu \mathrm{L}$ reaction mixture containing $12.5 \mu \mathrm{L}$ of $2 \mathrm{x}$ QuantiFast SYBR Green PCR Master Mix (Qiagen), $2.5 \mu \mathrm{L}$ of primers, and RNase free water. The PCR mixture was heated initially at $95^{\circ} \mathrm{C}$ for $5 \mathrm{~min}$ and then followed by 50 cycles of denaturation at $95^{\circ} \mathrm{C}$ for $10 \mathrm{~s}$ and combined annealing/extension at $60^{\circ} \mathrm{C}$ for $30 \mathrm{~s}$. This analysis was performed in triplicate. Data were analyzed using the comparative threshold cycle method.

2.4. ELISA. Commercially available ELISA kits (DYC41982, DY805, DY626, R\&D Systems Europe, Abingdon, United Kingdom, and HZ-5203, Hölzel Diagnostika, Cologne, Germany) were used for ELISA analyses according to the manufacturer's instructions to measure the levels of COX2 in cell lysates and of OPG, soluble RANKL, and PGE2 in cell supernatants. Using a microtiter plate reader (POWERWAVE $\mathrm{X}$; BioTek Instruments, Winooski, VT, USA) the absorbance was determined at $450 \mathrm{~nm}$ with wavelength correction at $540 \mathrm{~nm}$. COX2 data were normalized by total protein measured using Pierce BCA Protein Assay Kit (23227, Thermo Scientific, Pierce Biotechnology, Rockford, USA), while OPG, RANKL, and PGE2 data were normalized by the numbers of cells in the wells.

2.5. Statistical Analysis. Statistical analysis of the data was performed with GraphPad Prism 5 software (GraphPad Software Inc., San Diego, USA) using mean \pm standard deviation. One-way analysis of variance test (ANOVA) followed by Dunnett's or Tukey's post hoc tests was used to determine the presence of significant differences among experimental groups. Significant differences were considered when
$P<0.05$. All experiments were performed in triplicate and repeated at least twice.

\section{Results}

3.1. Stimulation of COX2 and OPG Expressions by F. nucleatum ATCC 25586. COX2 and OPG were constitutively produced by PDL cells. To mimic an inflammatory environment, cells were stimulated with $F$. nucleatum ATCC 25586 leading to a significant $(P<0.05)$ upregulation of the COX2 and OPG mRNA expression in a time-dependent manner. As shown in Figures 1(a) and 1(c), F. nucleatum ATCC 25586 had no significant effect on COX2 and OPG mRNA expression up to 12 hours, but at 24 hours it significantly $(P<0.05)$ increased the COX2 and OPG expressions. F. nucleatum ATCC 25586 enhanced significantly $(P<0.05)$ the mRNA expression of COX2 in a dose-dependent manner, whereas OPG was not influenced by the varying concentrations of bacteria at 24 hours (Figures 1(b) and 1(d)).

3.2. Stimulation of COX2 Expression by F. nucleatum ATCC 25586 via TLRs. In order to analyze whether F. nucleatum ATCC 25586 uses TLRs to upregulate COX2, cells were stimulated with F. nucleatum ATCC 25586 in the presence and absence of blocking antibodies against TLR2 and TLR4 for 24 hours. The results demonstrated that COX2 mRNA expression was decreased after treating PDL cells with antiTLRs (Figure 1(e)). The inhibition of the F. nucleatuminduced COX2 expression occurred for both anti-TLRs being more evident and significant $(P<0.05)$ for anti-TLR4.

\subsection{Regulation of F. nucleatum-Stimulated COX2 and PGE2} Syntheses by CTS. In order to study whether biomechanical loading modulates the F. nucleatum-induced effects on COX2 and PGE2, CTS was applied to PDL fibroblasts. As evidenced by ELISA, CTSL and CTSH alone had only small effects on COX2 and PGE2 syntheses. However, biomechanical loading modulated the effects of F. nucleatum ATCC 25586 on COX2 and PGE2 in PDL cells. When PDL cells were concomitantly stimulated with CTS and F. nucleatum ATCC 25586, CTS tended to increase the F. nucleatum-induced effects on COX2 production (Figure 2(a)). Furthermore, CTS aggravated the F. nucleatum-induced effects on the PGE2 production (Figures 2(b) and 2(c)). As compared to CTSL, $\mathrm{CTSH}$ caused a more pronounced and significant increase in the F. nucleatum-induced PGE production $(P<0.05)$ at 1 day and 3 days (Figures 2(b) and 2(c)).

3.4. Regulation of F. nucleatum-Induced RANKL and OPG Expressions by CTS. Next, we investigated the expression of RANKL and OPG in PDL cells challenged with F. nucleatum ATCC 25586 in the presence and absence of biomechanical loading. F. nucleatum ATCC 25586 tended to increase the RANKL expression at 1 day but not at 3 days, and significantly $(P<0.05)$, despite discrete, upregulated the OPG expression after both 1 day and 3 days (Figures 3(a)-3(d)). Whereas CTSL had no effects on RANKL and OPG expressions (data not shown), CTSH caused a significant $(P<0.05)$ upregulation of the F. nucleatum-induced RANKL expression 


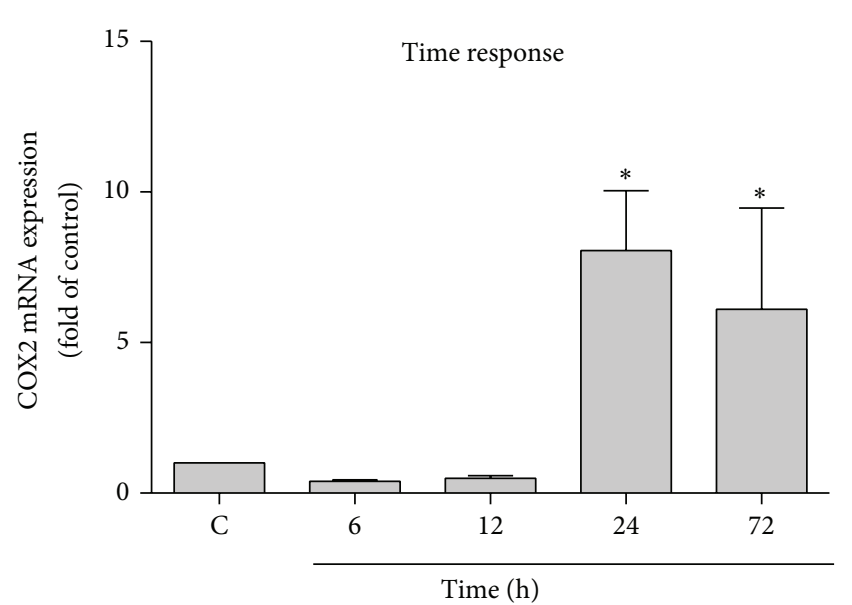

(a)

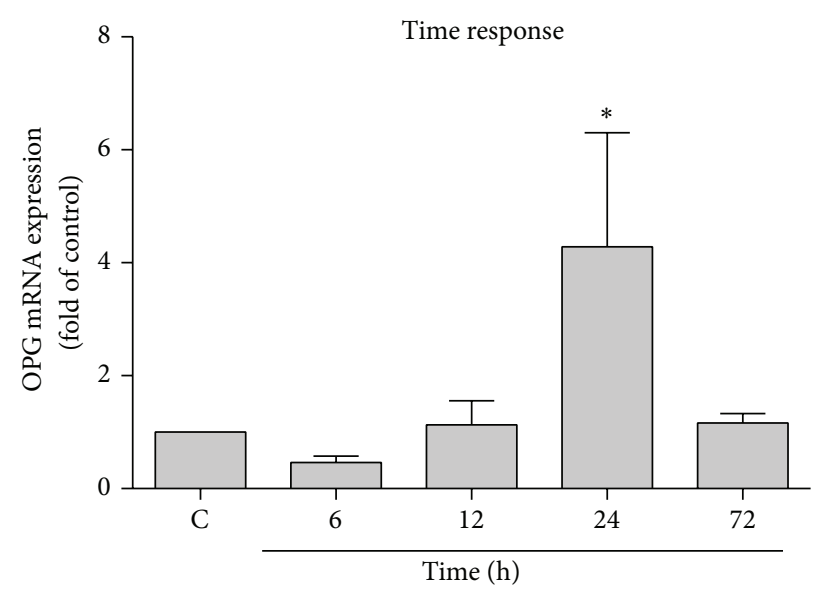

(c)

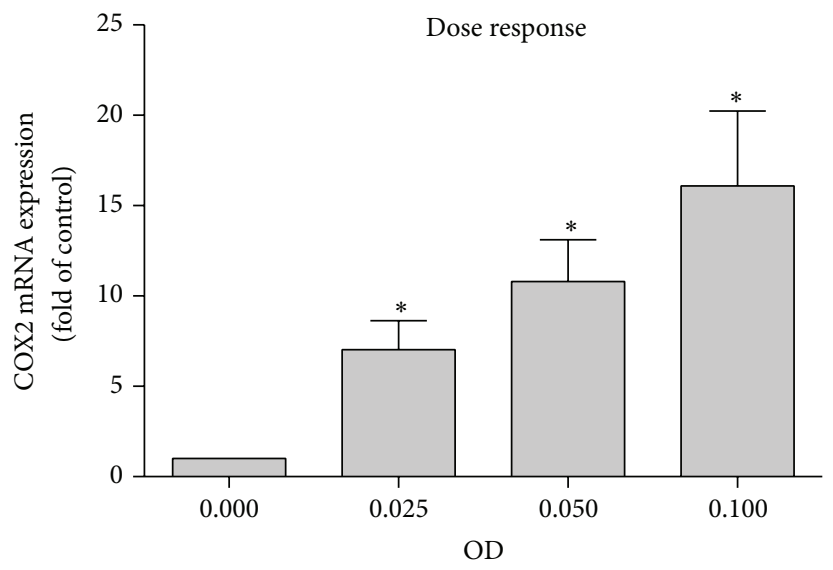

(b)

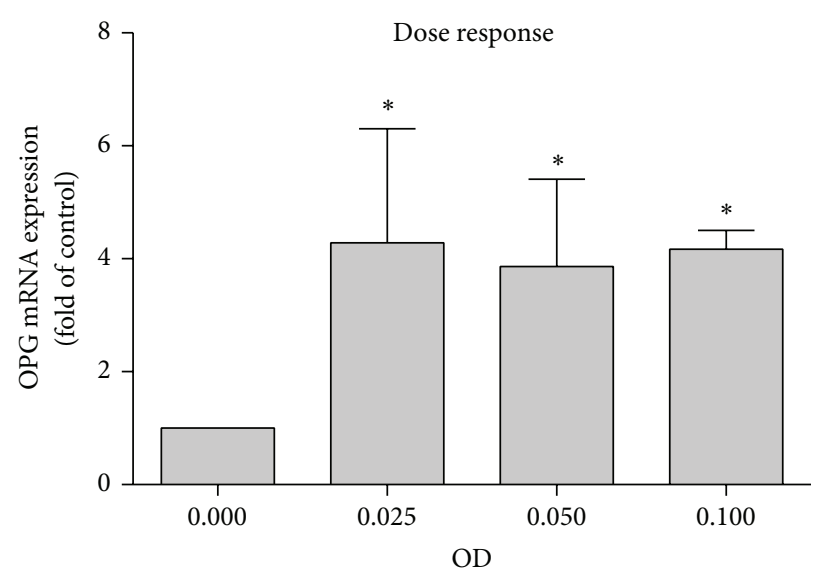

(d)

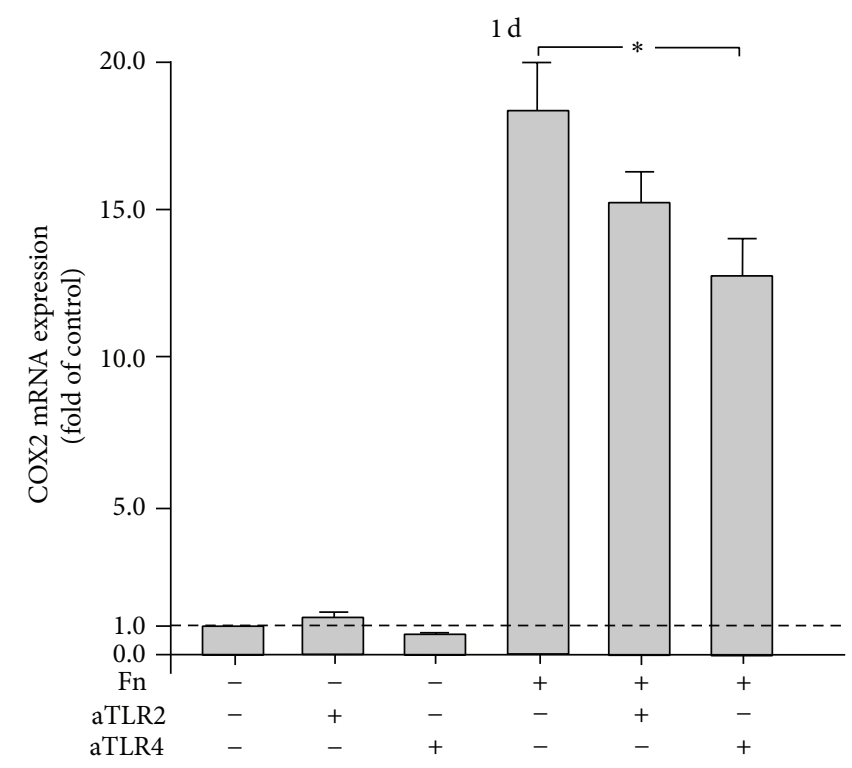

(e)

FIGURE 1: (a) COX2 expression in PDL cells stimulated by F. nucleatum ATCC 25586 over time. (b) COX2 expression in PDL cells stimulated by various concentrations of $F$. nucleatum ATCC 25586 at 1 day. (c) OPG expression in PDL cells stimulated by F. nucleatum ATCC 25586 over time. (d) OPG expression in PDL cells stimulated by various concentrations of F. nucleatum ATCC 25586 at 1 day. (e) COX2 expression in PDL cells stimulated by F. nucleatum ATCC 25586 (OD 0.025) in the presence or in the absence of anti-TLR2 or anti-TLR4 antibodies at 1 day. ${ }^{*}$ Significant difference between groups $(P<0.05)$. 


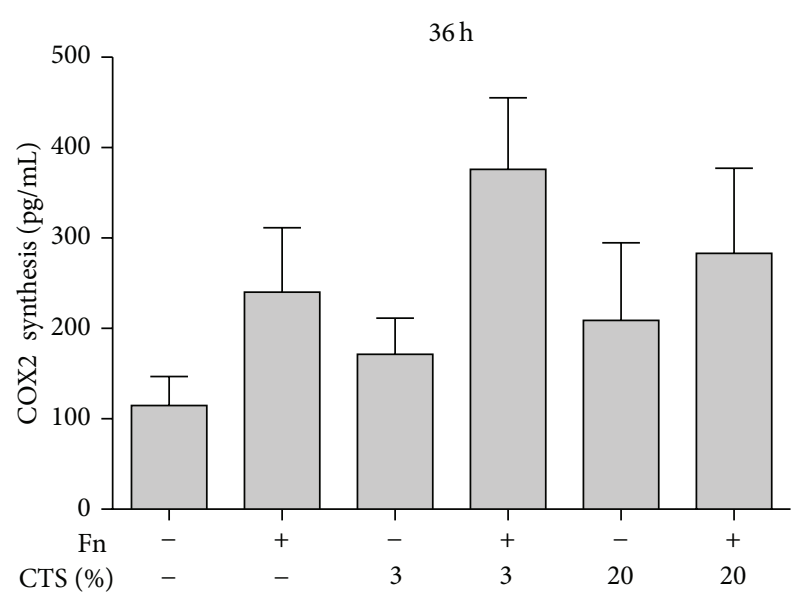

(a)

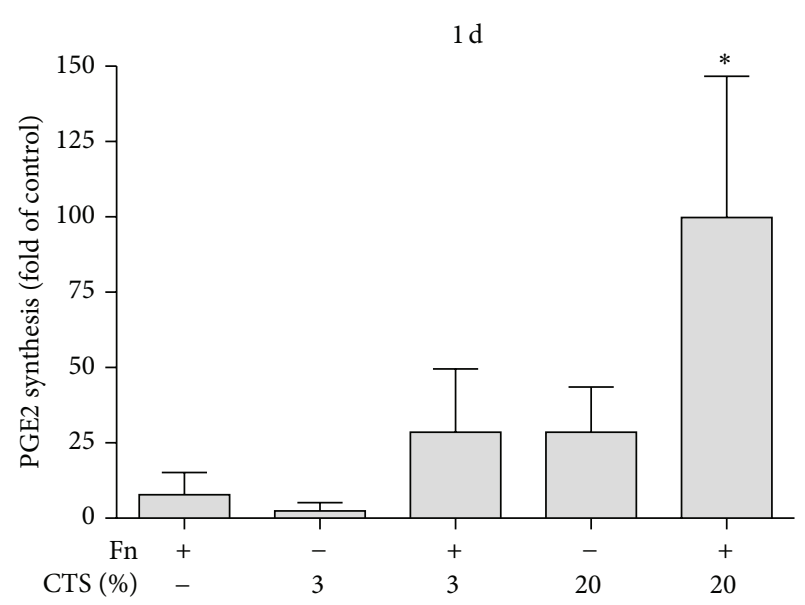

(b)

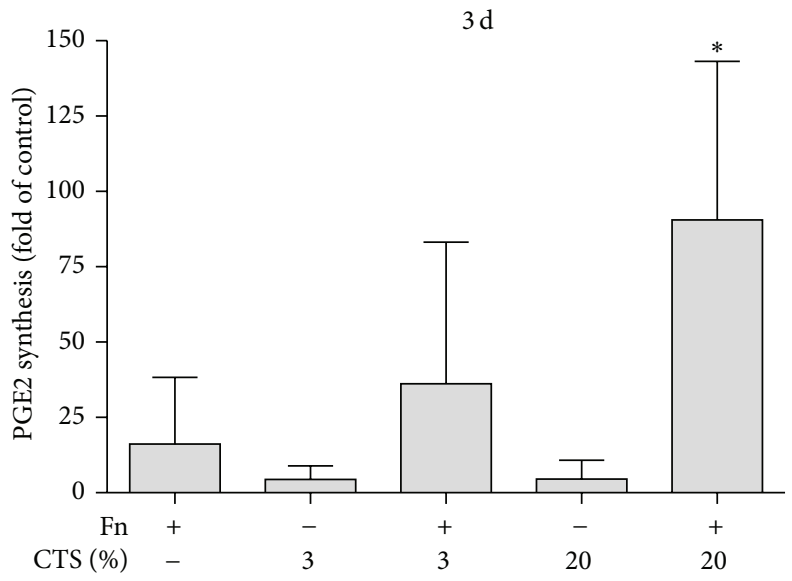

(c)

FIgURE 2: (a) Synthesis of COX2 in lysates of PDL cells treated with F. nucleatum ATCC 25586 and/or cyclic tensile strain (CTS) of low (CTSL, $3 \%$ ) and high (CTSH, 20\%) magnitudes at 36 hours. (b and c) Production of PGE2 in supernatants of PDL cells treated with F. nucleatum ATCC 25586 and/or CTSL and CTSH at 1 day (b) and 3 days (c). ${ }^{*}$ Significant difference compared to other groups $(P<0.05)$.

at 3 days and a significant $(P<0.05)$ downregulation of the $F$. nucleatum-induced OPG expression at 1 day and 3 days (Figures 3(a)-3(d)). Furthermore, CTSH increased significantly the RANKL/OPG ratio in the presence and absence of F. nucleatum ATCC 25586 at both time points (Figures 3(e) and 3(f)). As shown in Figures 4(a)-4(f), the effects of biomechanical strain were also observed at protein level, as analyzed by ELISA.

\section{Discussion}

Many attempts have been made to study the effects of inflammatory and/or mechanical stimulation on PDL cells [37-40]. Occasionally the results are ambiguous especially due to differences in methodology such as culture conditions, type of inflammatory induction, type of mechanical apparatus, and type of strain regime. Our study aimed to investigate in vitro whether biomechanical loading would modulate bacterial regulation of important proinflammatory and bone remodeling mediators in PDL cells. The main finding of this study was that a CTS stimulus enhanced the F. nucleatum-induced increase of COX2 and PGE2. The association of CTSH and F. nucleatum ATCC 25586 resulted in an RANKL/OPG ratio that is significantly higher when compared to F. nucleatum ATCC 25586 alone.

F. nucleatum ATCC 25586 upregulates COX2 via TLRs signaling in PDL cells, especially by TLR4 due to the fact that preincubation with TLR4 antibody resulted in significant inhibition of the F. nucleatum-induced COX2 stimulation. Also, F. nucleatum is probably using other pathways for signaling in PDL cells as our data from the TLR inhibition experiment showed only partial inhibition of COX2 expression after blocking the TLRs 2 and 4 . In addition, F. nucleatum was previously shown to stimulate TLR2 and 4 expressions in PDL cells [41]. Mechanical force driven by CTS to PDL cells increased COX2 production as previously demonstrated [11, 37]. When PDL cells were subjected to both stimuli, bacterial and mechanical force, COX2 production showed a tendency to be higher than the effect of each stimulus alone, and PGE2 expression and production were significantly increased in 


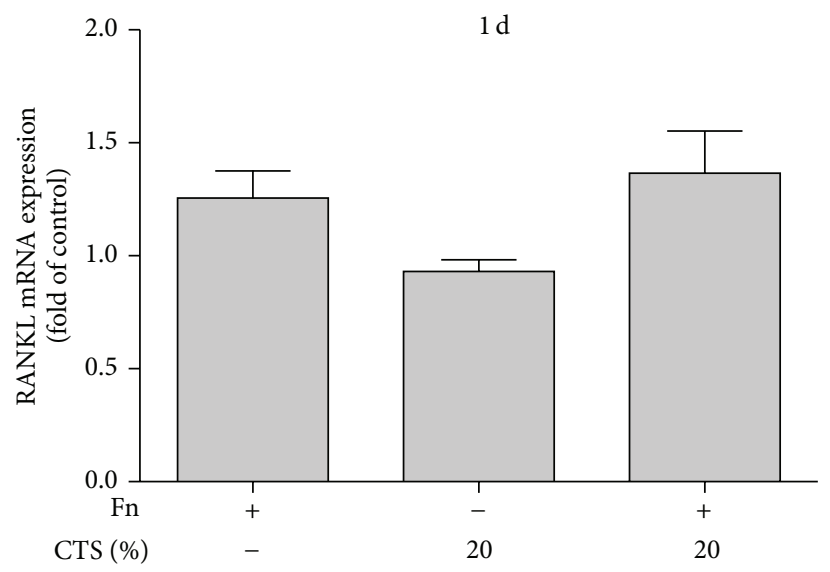

(a)

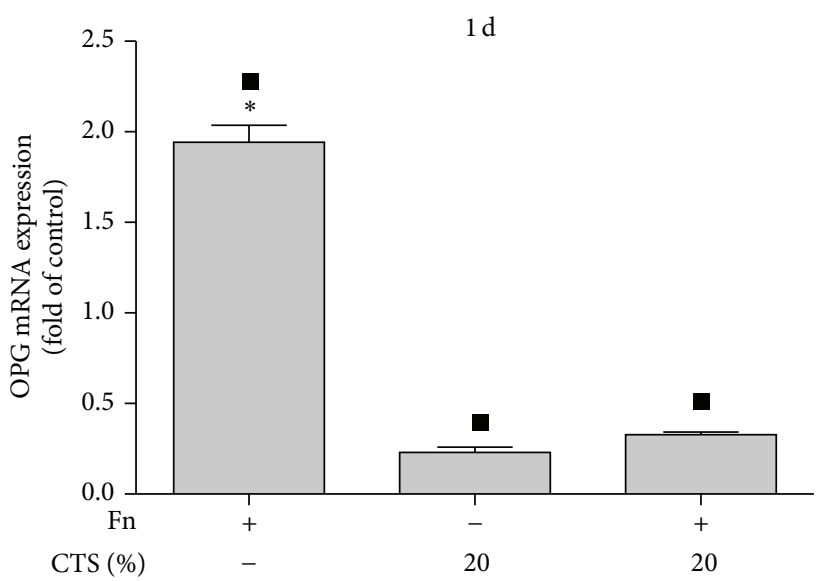

(c)

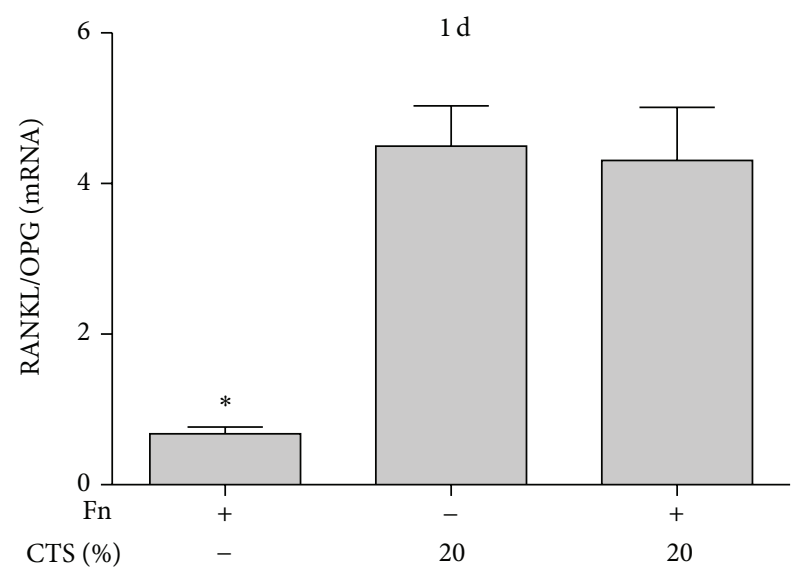

(e)

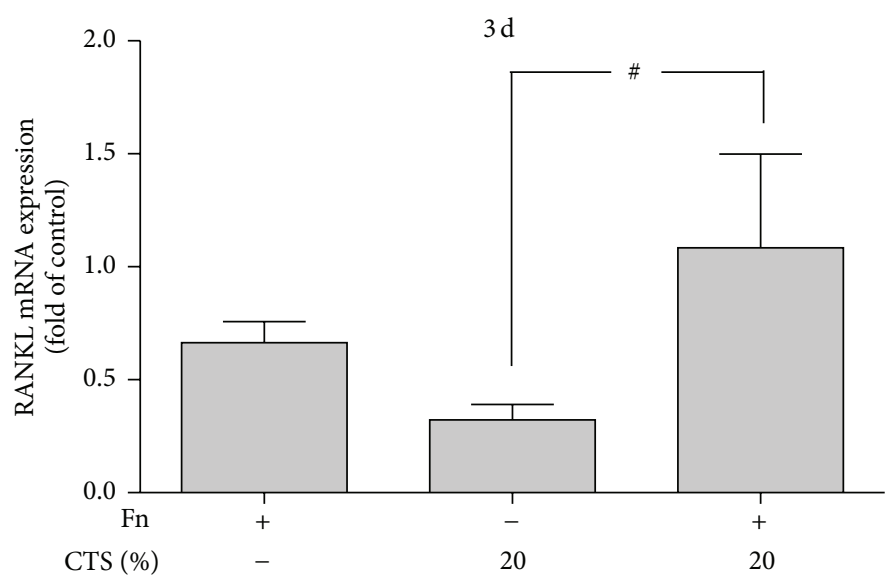

(b)

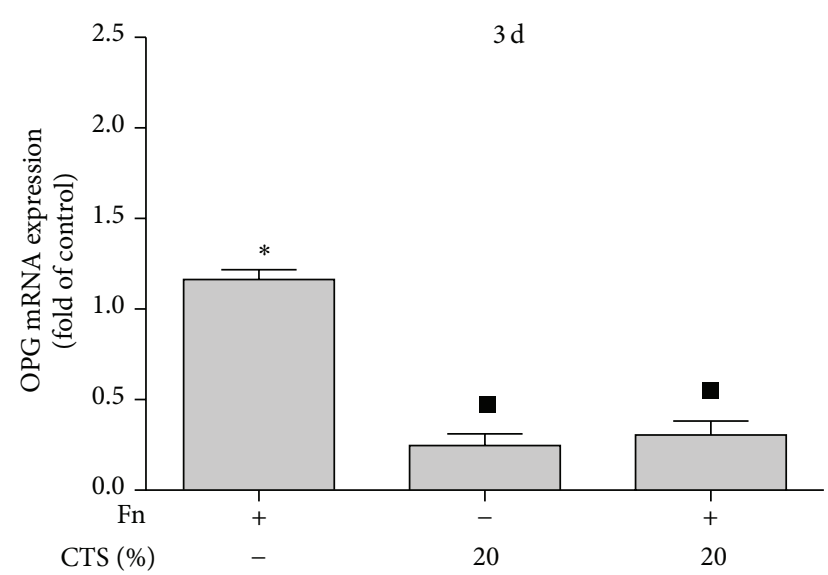

(d)

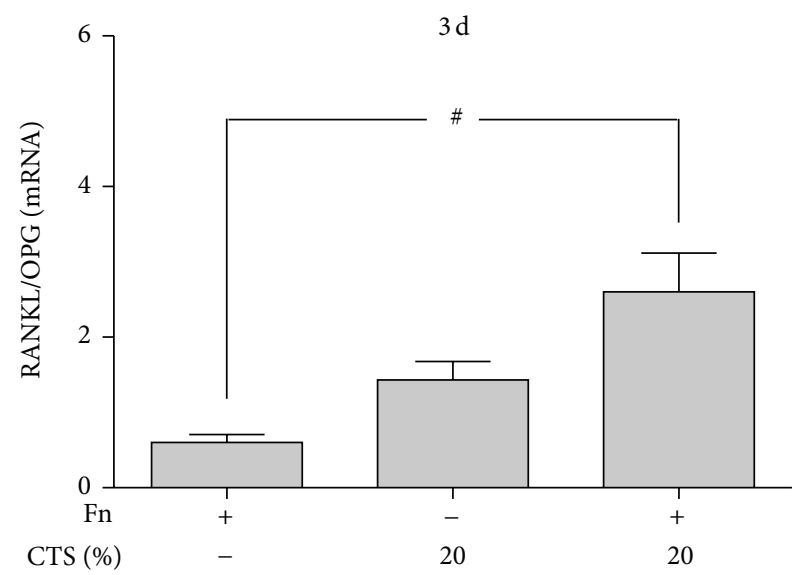

(f)

FIgURE 3: ( $a$ and b) RANKL expression in PDL cells stimulated by F. nucleatum ATCC 25586 and/or CTSH at 1 day (a) and 3 days (b). (c and d) OPG expression in PDL cells stimulated by F. nucleatum ATCC 25586 and/or CTSH at 1 day (c) and 3 days (d). (e and f) RANKL/OPG mRNA ratio in PDL cells stimulated by F. nucleatum ATCC 25586 and/or CTSH at 1 day (e) and 3 days (f). ${ }^{*}$ Significant difference compared to other groups $(P<0.05)$, "significant difference compared to control $(P<0.05)$, and ${ }^{\#}$ significant difference $(P<0.05)$.

this situation. Thus, mechanical force increased the effect of F. nucleatum ATCC 25586 on COX2-PGE2 production exhibiting a proinflammatory effect.

Studies have reported that PGE2 mediates bone resorption through the activation of osteoclasts and RANKL in response to mechanical stress in vitro [11] and in vivo [25]. Due to this fact, we have decided to investigate whether RANKL and OPG expression and production would be modulated by F. nucleatum ATCC 25586 and CTS in PDL cells. F. nucleatum ATCC 25586 induced the expression and 


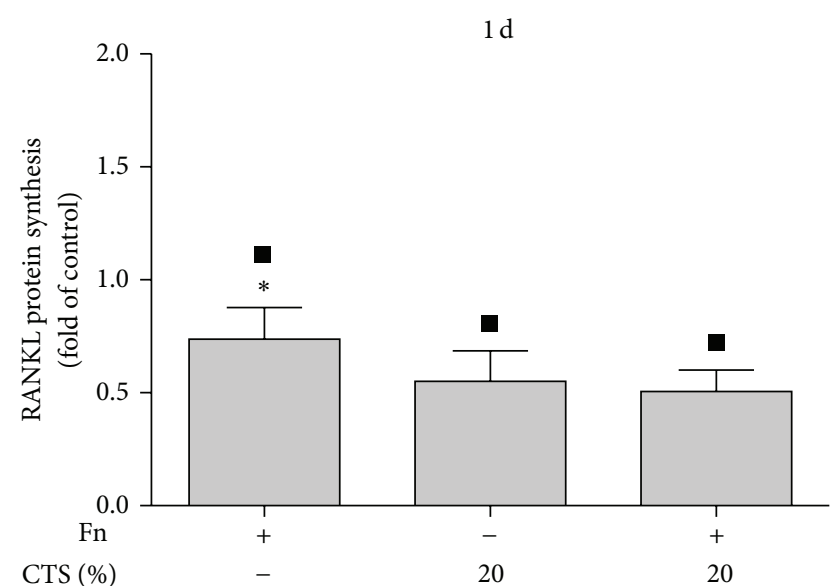

(a)

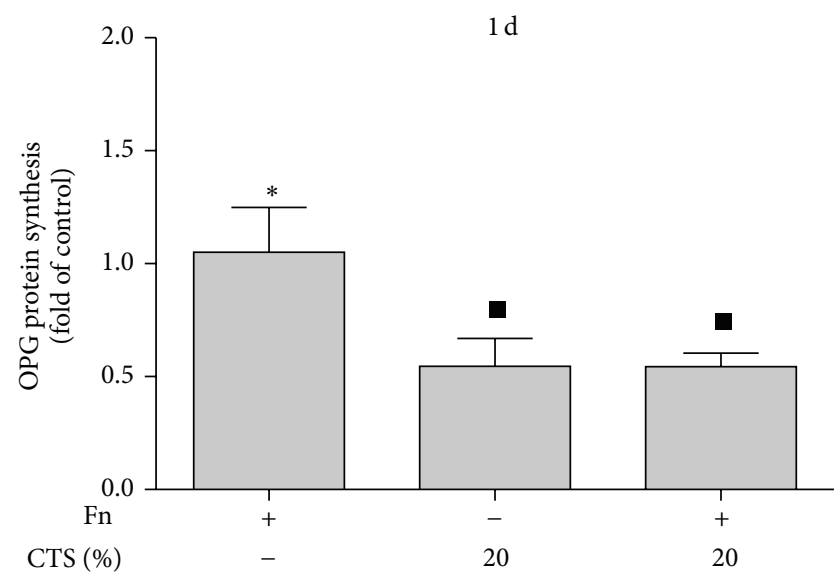

(c)

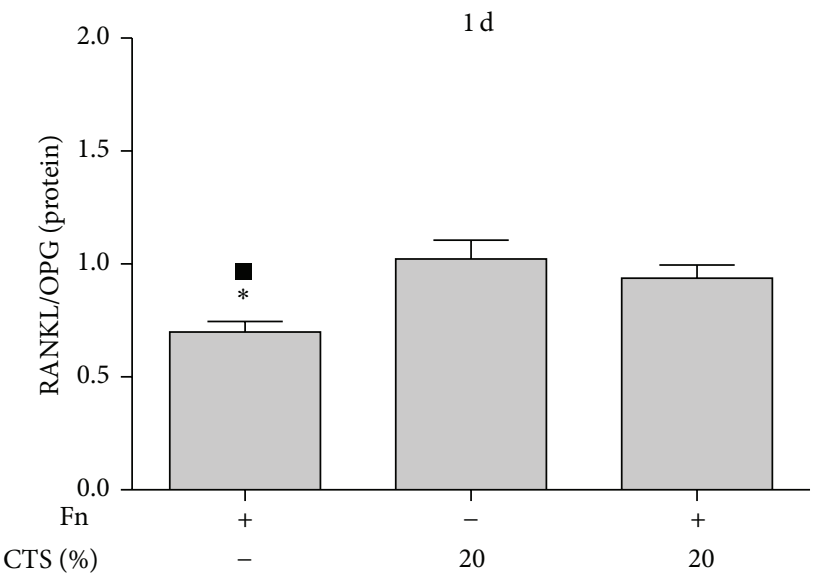

(e)

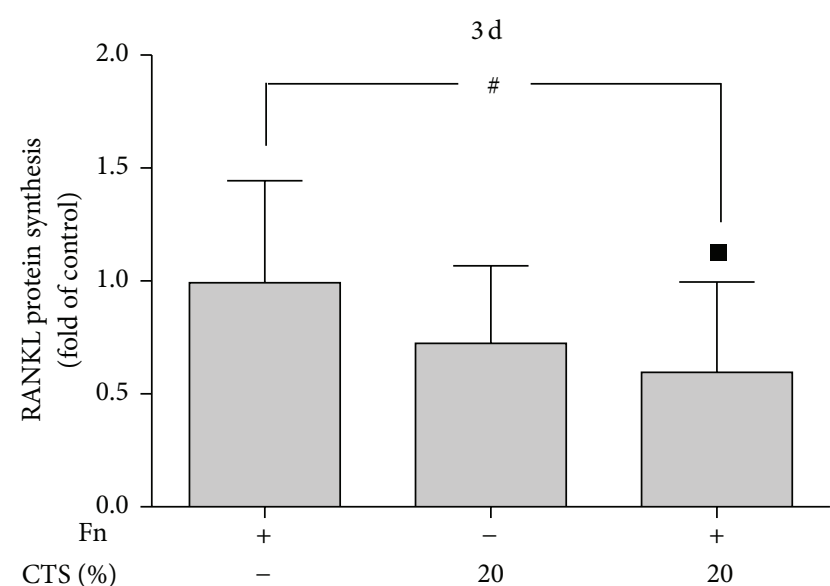

(b)

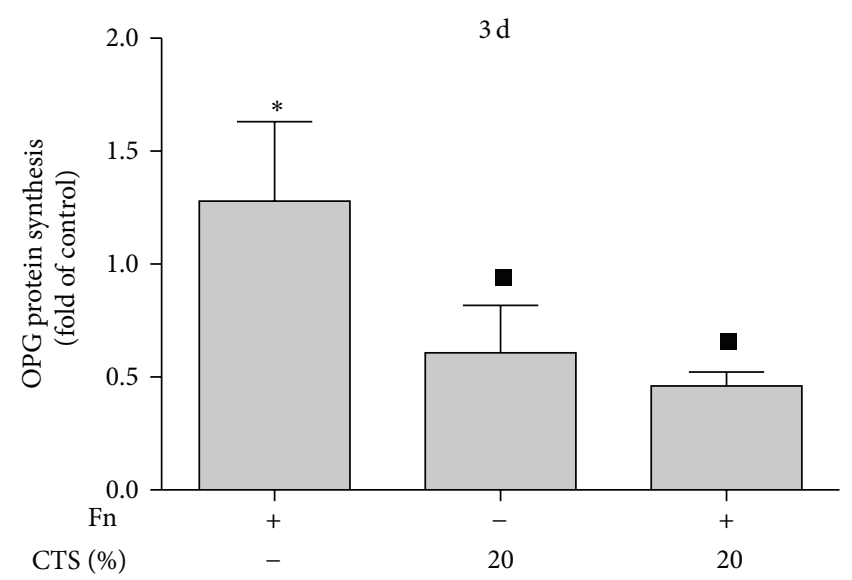

(d)

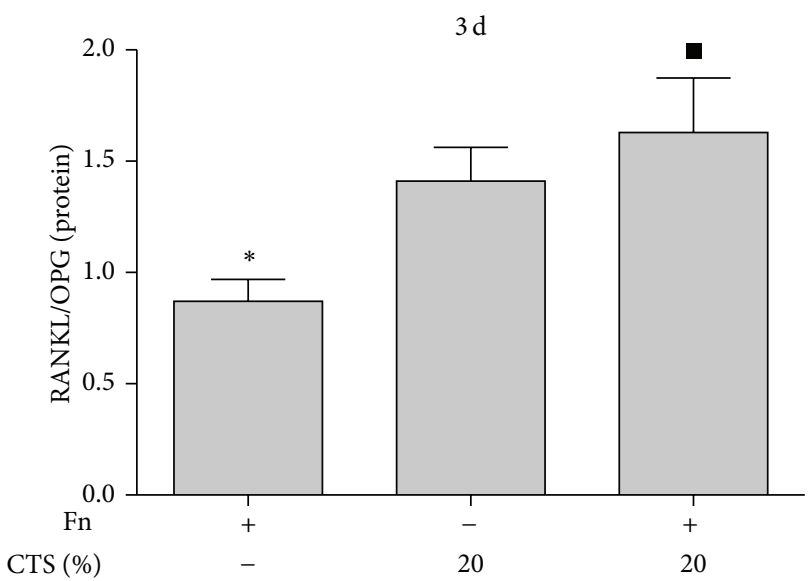

(f)

FIGURE 4: ( $\mathrm{a}$ and b) Synthesis of RANKL protein in supernatants of PDL cells stimulated by F. nucleatum ATCC 25586 and/or CTSH at 1 day (a) and 3 days (b). (c and d) Synthesis of OPG protein in supernatants of PDL cells stimulated by F. nucleatum ATCC 25586 and/or CTSH at 1 day (c) and 3 days (d). (e and f) RANKL/OPG protein ratio in supernatants of PDL cells stimulated by F. nucleatum ATCC 25586 and/or $\mathrm{CTSH}$ at 1 day (e) and 3 days (f). ${ }^{*}$ Significant difference compared to other groups $(P<0.05)$, ' significant difference compared to control $(P<0.05)$, and ${ }^{\#}$ significant difference $(P<0.05)$. 
synthesis of RANKL and OPG in PDL cells at both time points, 1 day and 3 days. CTSH in the presence of F. nucleatum ATCC 25586 inhibited the expression and synthesis of OPG while it stimulated the increase in RANKL. As a result, the RANKL/OPG ratio was low for the groups stimulated by F. nucleatum ATCC 25586 alone and high for the other two groups, CTSH alone and CTSH associated with F. nucleatum ATCC 25586.

In our study, CTS aggravated F. nucleatum-induced increase in the production of COX2 and PGE2 and reduced the expression and production of OPG, leading to an increase in RANKL/OPG ratio in this group compared to F. nucleatum ATCC 25586 alone. These results suggest an exacerbated proinflammatory and bone resorptive effect of CTS in the presence of bacteria. Our results corroborate in part other previous studies in that biomechanical loading can exert proinflammatory effects under inflammatory conditions in PDL cells [37, 40, 42]. All of these studies applied CTS of low and high strains in cells treated with IL- $1 \beta$. Some of them reported that high strain was proinflammatory and enhanced the IL- $1 \beta$-induced production of inflammatory mediators $[40,42]$, while another study reported a proinflammatory effect for both strains only at 1 day [37]. Long et al. [40] have detected an anti-inflammatory effect of CTSL and Nokhbehsaim et al. [37] found this same effect when cells were subjected to long-term application of CTS. In addition to the proinflammatory effect of biomechanical loading, mechanical stress driven by hydrostatic pressure has been shown to intensify the production of proinflammatory cytokines in PDL cells stimulated with periodontopathogenic bacteria [39]. The contradiction in the results exists especially due to differences in experimental features, for example, the type of inflammatory mediator that is being evaluated and the type of force that is being used.

Some studies reported that PDL cells express RANKL in response to mechanical stress [21, 35], while other studies reported PDL cells do not express RANKL [33] or express low levels of RANKL [34]. Regarding the expression of OPG, downregulation was detected in response to CTS in PDL cells [33]. Corroborating this study, our results also revealed downregulation of OPG in response to CTS and, in addition, an inhibitory effect of CTS on F. nucleatum-induced increase in OPG expression and protein synthesis. On the other hand, in another study, PDL cells subjected to CTS have expressed high levels of OPG and this effect was inhibited after concomitant stimulation with LPS [34]. Although contradictions can be observed in the literature regarding OPG expression after CTS stimulus in all studies, RANKL/OPG ratio increased when both CTS and inflammatory challenge were associated, suggesting that those conditions together have a bone resorptive effect.

In addition, when osteoblasts are cultured with inflammatory conditioned medium and subjected to CTS, an upregulation of $\mathrm{c}$-fos and reduction of osteogenicity were observed [43]. C-fos is a transcription factor important for the activation of genes involved in osteoclastogenesis [44]. This study shows that CTS in combination with inflammation is impairing the osteogenic capacity of osteoblasts. Although we have not evaluated c-fos, our in vitro study demonstrates a proinflammatory and bone resorptive (increase in the RANKL/OPG ratio) effect of CTS when associated with F. nucleatum ATCC 25586.

Periodontitis has a polymicrobial nature as it is originated from a complex bacterial biofilm. In order to mimic an inflammatory infection in vitro, F. nucleatum ATCC 25586, which is a gram-negative and anaerobic microorganism associated with both gingivitis and periodontitis, was used. In our study, F. nucleatum ATCC 25586 upregulated COX2, PGE2, and OPG syntheses in PDL cells. F. nucleatum ATCC 25586 is considered as a bridge bacterium because it is located in the middle of the subgingival biofilm inducing the adhesion of late colonizers during plaque development by coaggregation $[45,46]$. F. nucleatum ATCC 25586 can invade some cells and help other periodontopathogens to invade host cells $[47,48]$. However, more studies are necessary to evaluate whether other microorganisms associated with periodontal diseases are also able to activate the production of the mediators that we have evaluated in the present study. Another limitation of this study is that it did not examine the involvement of COX2-PGE2 on the RANKL/OPG ratio when cells were concomitantly stimulated by biomechanical loading and bacteria. This could be shown by blocking COX2 with indomethacin, for example. However, a recent study demonstrated that COX2 inhibition with celecoxib resulted in RANKL downregulation and osteoclastogenesis reduction in PDL cells stimulated with heat-inactivated bacteria [49].

The sRANKL ELISA kit used in the present study can be interfered by OPG, according to the manufacturer's datasheet. In our samples, the OPG concentration was higher than $156 \mathrm{pg} / \mathrm{mL}$, so that interference cannot be completely excluded in our experiments. However, this ELISA kit is frequently used by other investigators and it is difficult to avoid OPG in the samples.

The periodontium is constantly subjected to complex biomechanical forces such as mastication, orthodontic tooth movement, and functional occlusal habits. In the present study, we investigated the interactions of biomechanical forces and inflammatory signals in PDL cells. Our results revealed that biomechanical loading enhanced the F. nucleatum-induced upregulation of COX2 and PGE2 production and the RANKL/OPG ratio in PDL cells. These findings indicate that biomechanical loading can aggravate the destructive effects of inflammation on periodontal tissues during periodontitis. The strain regimens used in our experiments showed that biomechanical loading has a proinflammatory effect favoring the actions of F. nucleatum ATCC 25586. Previous studies corroborate our results [37, 40, 42].

In summary, our findings provide original evidence that CTS can enhance the synthesis of molecules associated with inflammation and bone resorption. Therefore, biomechanical, such as orthodontic or occlusal, loading may enhance the bacterial-induced inflammation and destruction in periodontitis. 


\section{Conflict of Interests}

The authors declare that there is no conflict of interests regarding the publication of this paper.

\section{Authors' Contribution}

Andressa Vilas Boas Nogueira and Marjan Nokhbehsaim contributed equally to this work.

\section{Acknowledgments}

The present study was supported by the following Grants: São Paulo Research Foundation (FAPESP: 2010/07771-4, 2011/13752-5), Coordenação de Aperfeiçoamento de Pessoal de Nível Superior (CAPES: 2385-11-2), German Research Foundation (DFG: KFO208/TP4), and Medical Faculty of the University of Bonn. The authors would like to thank Mrs. Ramona Menden, Dr. Svenja Memmert, and Dr. Susanne Reimann for their great support.

\section{References}

[1] M. Sanz and A. J. van Winkelhoff, "Periodontal infections: understanding the complexity-consensus of the Seventh European Workshop on Periodontology," Journal of Clinical Periodontology, vol. 38, no. 11, pp. 3-6, 2011.

[2] D. T. Graves and D. Cochran, "The contribution of interleukin1 and tumor necrosis factor to periodontal tissue destruction," Journal of Periodontology, vol. 74, no. 3, pp. 391-401, 2003.

[3] R. Górska, H. Gregorek, J. Kowalski, A. Laskus-Perendyk, M. Syczewska, and K. Madaliński, "Relationship between clinical parameters and cytokine profiles in inflamed gingival tissue and serum samples from patients with chronic periodontitis," Journal of Clinical Periodontology, vol. 30, no. 12, pp. 1046-1052, 2003.

[4] Y. Zhong, G. D. Slade, J. D. Beck, and S. Offenbacher, "Gingival crevicular fluid interleukin- $1 \beta$, prostaglandin E2 and periodontal status in a community population," Journal of Clinical Periodontology, vol. 34, no. 4, pp. 285-293, 2007.

[5] N. Silva, N. Dutzan, M. Hernandez et al., "Characterization of progressive periodontal lesions in chronic periodontitis patients: levels of chemokines, cytokines, matrix metalloproteinase-13, periodontal pathogens and inflammatory cells," Journal of Clinical Periodontology, vol. 35, no. 3, pp. 206-214, 2008.

[6] D. L. Cochran, "Inflammation and bone loss in periodontal disease," Journal of Periodontology, vol. 79, no. 8, pp. 1569-1576, 2008.

[7] V. Krishnan and Z. Davidovitch, "On a path to unfolding the biological mechanisms of orthodontic tooth movement," Journal of Dental Research, vol. 88, no. 7, pp. 597-608, 2009.

[8] A. V. Boas Nogueira, J. A. Chaves de Souza, Y. J. Kim, M. Damiao de Sousa-Neto, C. Chan Cirell, and J. A. Cirelli, "Orthodontic force increases interleukin-1beta and tumor necrosis factoralpha expression and alveolar bone loss in periodontitis," Journal of Periodontology, vol. 84, no. 9, pp. 1319-1326, 2013.

[9] I. Ericsson and B. Thilander, "Orthodontic forces and recurrence of periodontal disease. An experimental study in the dog," American Journal of Orthodontics, vol. 74, no. 1, pp. 41-50, 1978.
[10] J. L. Wennström, B. L. Stokland, S. Nyman, and B. Thilander, "Periodontal tissue response to orthodontic movement of teeth with infrabony pockets," American Journal of Orthodontics and Dentofacial Orthopedics, vol. 103, no. 4, pp. 313-319, 1993.

[11] N. Shimizu, Y. Ozawa, M. Yamaguchi, T. Goseki, K. Ohzeki, and Y. Abiko, "Induction of COX-2 expression by mechanical tension force in human periodontal ligament cells," Journal of Periodontology, vol. 69, no. 6, pp. 670-677, 1998.

[12] S. Offenbacher, B. M. Odle, R. C. Gray, and T. E. van Dyke, "Crevicular fluid prostaglandin E levels as a measure of the periodontal disease status of adult and juvenile periodontitis patients," Journal of Periodontal Research, vol. 19, no. 1, pp. 1-13, 1984.

[13] S. Offenbacher, B. M. Odle, and T. E. van Dyke, "The use of crevicular fluid prostaglandin E2 levels as a predictor of periodontal attachment loss," Journal of Periodontal Research, vol. 21, no. 2, pp. 101-112, 1986.

[14] S. Offenbacher, P. A. Heasman, and J. G. Collins, "Modulation of host PGE2 secretion as a determinant of periodontal disease expression," Journal of Periodontology, vol. 64, no. 5, pp. 432444, 1993.

[15] R. S. Morton and A. I. Dongari-Bagtzoglou, "Cyclooxygenase-2 is upregulated in inflamed gingival tissues," Journal of Periodontology, vol. 72, no. 4, pp. 461-469, 2001.

[16] S. Nyman, H. E. Schroeder, and J. Lindhe, "Suppression of inflammation and bone resorption by indomethacin during experimental periodontitis in dogs," Journal of Periodontology, vol. 50, no. 9, pp. 450-461, 1979.

[17] V. Krishnan and Z. Davidovitch, "Cellular, molecular, and tissue-level reactions to orthodontic force," American Journal of Orthodontics and Dentofacial Orthopedics, vol. 129, no. 4, pp. 469.el-469.e32, 2006.

[18] X. H. Liu, A. Kirschenbaum, S. Yao, and A. C. Levine, "Interactive effect of interleukin- 6 and prostaglandin E2 on osteoclastogenesis via the OPG/RANKL/RANK system," Annals of the New York Academy of Sciences, vol. 1068, no. 1, pp. 225-233, 2006.

[19] H. Oka, M. Miyauchi, H. Furusho, T. Nishihara, and T. Takata, "Oral administration of prostaglandin E2-specific receptor 4 antagonist inhibits lipopolysaccharide-induced osteoclastogenesis in rat periodontal tissue," Journal of Periodontology, vol. 83, no. 4, pp. 506-513, 2012.

[20] C. Jacobs, C. Walter, T. Ziebart et al., "Induction of IL-6 and MMP-8 in human periodontal fibroblasts by static tensile strain," Clinical Oral Investigations, vol. 18, no. 3, pp. 901-908, 2014.

[21] H. Kanzaki, M. Chiba, Y. Shimizu, and H. Mitani, "Periodontal ligament cells under mechanical stress induce osteoclastogenesis by receptor activator of nuclear factor $\kappa \mathrm{B}$ ligand upregulation via prostaglandin E2 synthesis," Journal of Bone and Mineral Research, vol. 17, no. 2, pp. 210-220, 2002.

[22] Z. Davidovitch, J. L. Shanfeld, and P. C. Montgomery, "Biochemical mediators of the effect of mechanical forces and electric currents on mineralized tissues," Calcified Tissue International, vol. 36, no. 1, pp. S86-S97, 1984.

[23] M. Yamaguchi, N. Shimizu, T. Goseki et al., "Effect of different magnitudes of tension force on prostaglandin E2 production by human periodontal ligament cells," Archives of Oral Biology, vol. 39, no. 10, pp. 877-884, 1994.

[24] G. Yang, H. J. Im, and J. H. C. Wang, "Repetitive mechanical stretching modulates IL- $1 \beta$ induced COX-2, MMP- 1 expression, and PGE2 production in human patellar tendon fibroblasts," Gene, vol. 363, no. 1-2, pp. 166-172, 2005. 
[25] S. Saito, P. Ngan, T. Rosol et al., "Involvement of PGE synthesis in the effect of intermittent pressure and interleukin- $1 \beta$ on bone resorption," Journal of Dental Research, vol. 70, no. 1, pp. 27-33, 1991.

[26] A. Dudic, S. Kiliaridis, A. Mombelli, and C. Giannopoulou, "Composition changes in gingival crevicular fluid during orthodontic tooth movement: comparisons between tension and compression sides," European Journal of Oral Sciences, vol. 114, no. 5, pp. 416-422, 2006.

[27] K. Yamasaki, Y. Shibata, and T. Fukuhara, "The effect of prostaglandins on experimental tooth movement in monkeys (Macaca fuscata)," Journal of Dental Research, vol. 61, no. 12, pp. 1444-1446, 1982.

[28] B. J. Leiker, R. S. Nanda, G. F. Currier, R. I. Howes, and P. K. Sinha, "The effects of exogenous prostaglandins on orthodontic tooth movement in rats," American Journal of Orthodontics and Dentofacial Orthopedics, vol. 108, no. 4, pp. 380-388, 1995.

[29] M. Seifi, B. Eslami, and A. S. Saffar, "The effect of prostaglandin E2 and calcium gluconate on orthodontic tooth movement and root resorption in rats," European Journal of Orthodontics, vol. 25, no. 2, pp. 199-204, 2003.

[30] M. Caglaroglu and A. Erdem, "Histopathologic investigation of the effects of prostaglandin E2 administered by different methods on tooth movement and bone metabolism," Korean Journal of Orthodontics, vol. 42, no. 3, pp. 118-128, 2012.

[31] D. Liu, J. K. Xu, L. Figliomeni et al., "Expression of RANKL and OPG mRNA in periodontal disease: possible involvement in bone destruction," International Journal of Molecular Medicine, vol. 11, no. 1, pp. 17-21, 2003.

[32] L. C. Hofbauer, S. Khosla, C. R. Dunstan, D. L. Lacey, W. J. Boyle, and B. L. Riggs, "The roles of osteoprotegerin and osteoprotegerin ligand in the paracrine regulation of bone resorption," Journal of Bone and Mineral Research, vol. 15, no. 1, pp. 2-12, 2000.

[33] M. N. Pinkerton, D. C. Wescott, B. J. Gaffey, K. T. Beggs, T. J. Milne, and M. C. Meikle, "Cultured human periodontal ligament cells constitutively express multiple osteotropic cytokines and growth factors, several of which are responsive to mechanical deformation," Journal of Periodontal Research, vol. 43, no. 3, pp. 343-351, 2008.

[34] K. Tsuji, K. Uno, G. X. Zhang, and M. Tamura, "Periodontal ligament cells under intermittent tensile stress regulate mRNA expression of osteoprotegerin and tissue inhibitor of matrix metalloprotease-1 and -2," Journal of Bone and Mineral Metabolism, vol. 22, no. 2, pp. 94-103, 2004.

[35] T. Yamamoto, M. Kita, I. Kimura et al., "Mechanical stress induces expression of cytokines in human periodontal ligament cells," Oral Diseases, vol. 12, no. 2, pp. 171-175, 2006.

[36] M. Nokhbehsaim, B. Deschner, J. Winter et al., "Interactions of regenerative, inflammatory and biomechanical signals on bone morphogenetic protein-2 in periodontal ligament cells," Journal of Periodontal Research, vol. 46, no. 3, pp. 374-381, 2011.

[37] M. Nokhbehsaim, B. Deschner, J. Winter et al., "Contribution of orthodontic load to inflammation-mediated periodontal destruction," Journal of Orofacial Orthopedics, vol. 71, no. 6, pp. 390-402, 2010.

[38] A. V. Nogueira, M. Nokhbehsaim, S. Eick et al., "Regulation of visfatin by microbial and biomechanical signals in PDL cells," Clinical Oral Investigations, vol. 18, no. 1, pp. 171-178, 2014.

[39] T. Yamamoto, M. Kita, K. Yamamoto, Y. Akamatsu, F. Oseko, and N. Kanamura, "Mechanical stress enhances production of cytokines in human periodontal ligament cells induced by Porphyromonas gingivalis," Archives of Oral Biology, vol. 56, no. 3, pp. 251-257, 2011.

[40] P. Long, J. Hu, N. Piesco, M. Buckley, and S. Agarwal, "Low magnitude of tensile strain inhibits IL-1 $\beta$-dependent induction of pro-inflammatory cytokines and induces synthesis of IL-10 in human periodontal ligament cells in vitro," Journal of Dental Research, vol. 80, no. 5, pp. 1416-1420, 2001.

[41] Y. Sun, R. Shu, C. L. Li, and M. Z. Zhang, "Gram-negative periodontal bacteria induce the activation of Toll-like receptors 2 and 4 , and cytokine production in human periodontal ligament cells," Journal of Periodontology, vol. 81, no. 10, pp. 1488-1496, 2010.

[42] P. Long, F. Liu, N. P. Piesco, R. Kapur, and S. Agarwal, "Signaling by mechanical strain involves transcriptional regulation of proinflammatory genes in human periodontal ligament cells in vitro," Bone, vol. 30, no. 4, pp. 547-552, 2002.

[43] Y. Wang, H. Wang, Q. Ye et al., "Co-regulation of LPS and tensile strain downregulating osteogenicity via c-fos expression," Life Sciences, vol. 93, no. 1, pp. 38-43, 2013.

[44] H. Takayanagi, S. Kim, T. Koga et al., "Induction and activation of the transcription factor NFATc1 (NFAT2) integrate RANKL signaling in terminal differentiation of osteoclasts," Developmental Cell, vol. 3, no. 6, pp. 889-901, 2002.

[45] P. E. Kolenbrander, N. Ganeshkumar, F. J. Cassels, and C. V. Hughes, "Coaggregation: specific adherence among human oral plaque bacteria," FASEB Journal, vol. 7, no. 5, pp. 406-413, 1993.

[46] V. Zijnge, M. B. M. van Leeuwen, J. E. Degener et al., "Oral biofilm architecture on natural teeth," PLoS ONE, vol. 5, no. 2, Article ID e9321, 2010.

[47] A. Saito, S. Inagaki, R. Kimizuka et al., "Fusobacterium nucleatum enhances invasion of human gingival epithelial and aortic endothelial cells by Porphyromonas gingivalis," FEMS Immunology and Medical Microbiology, vol. 54, no. 3, pp. 349355, 2008.

[48] G. Dabija-Wolter, M. R. Cimpan, D. E. Costea et al., "Fusobacterium nucleatum enters normal human oral fibroblasts in vitro," Journal of Periodontology, vol. 80, no. 7, pp. 1174-1183, 2009.

[49] P. Römer, J. Köstler, V. Koretsi, and P. Proff, "Endotoxins potentiate COX-2 and RANKL expression in compressed PDL cells," Clinical Oral Investigations, vol. 17, no. 9, pp. 2041-2048, 2013. 


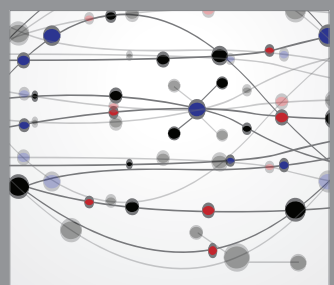

The Scientific World Journal
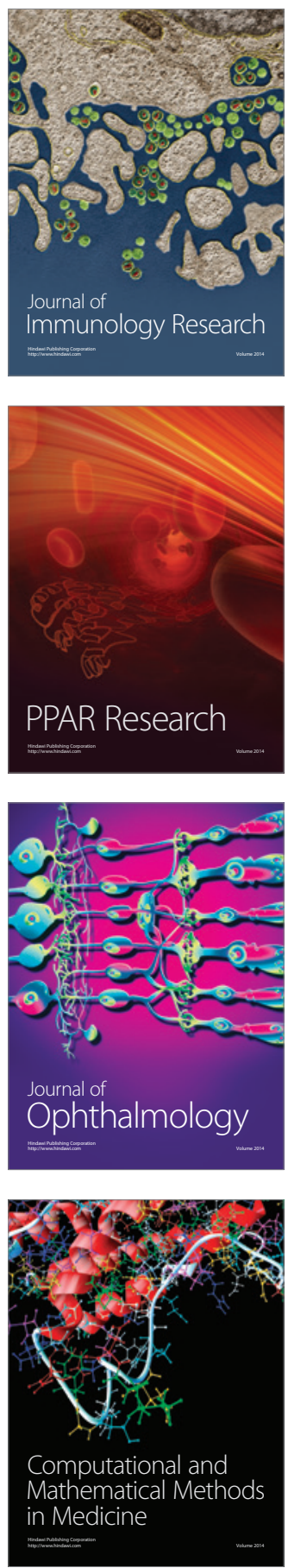

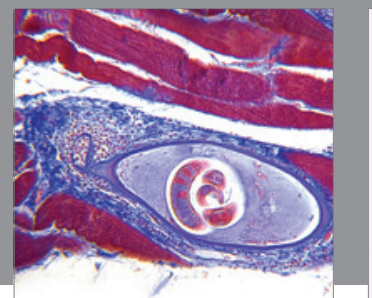

Gastroenterology

Research and Practice
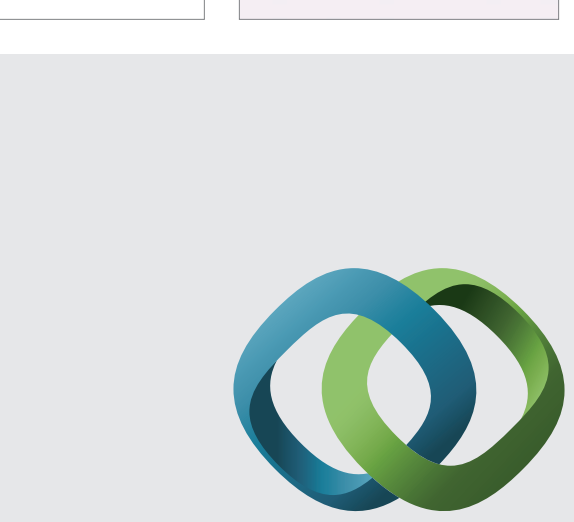

\section{Hindawi}

Submit your manuscripts at

http://www.hindawi.com
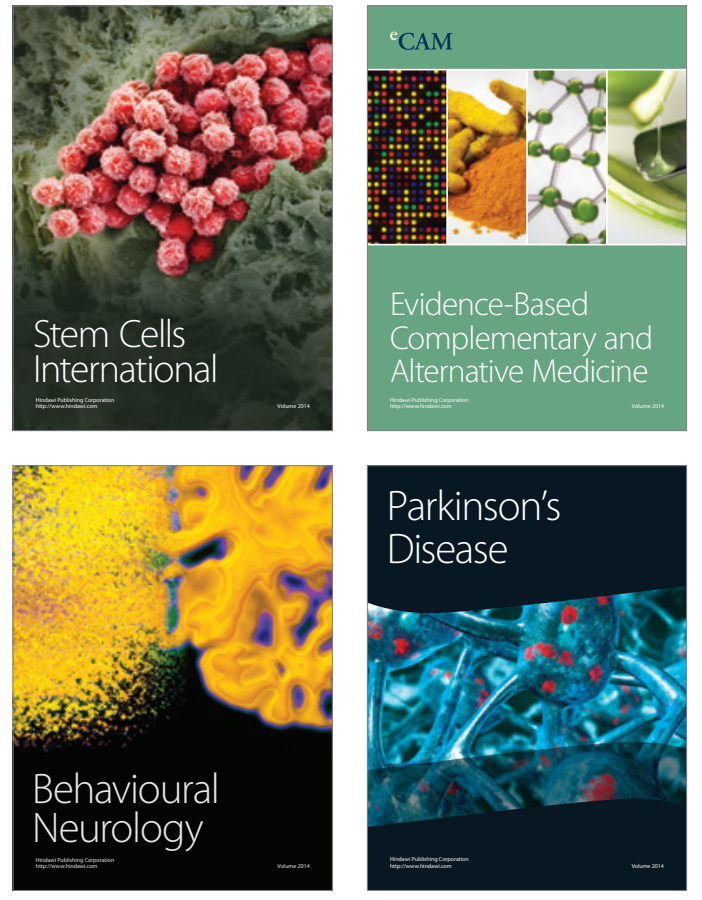
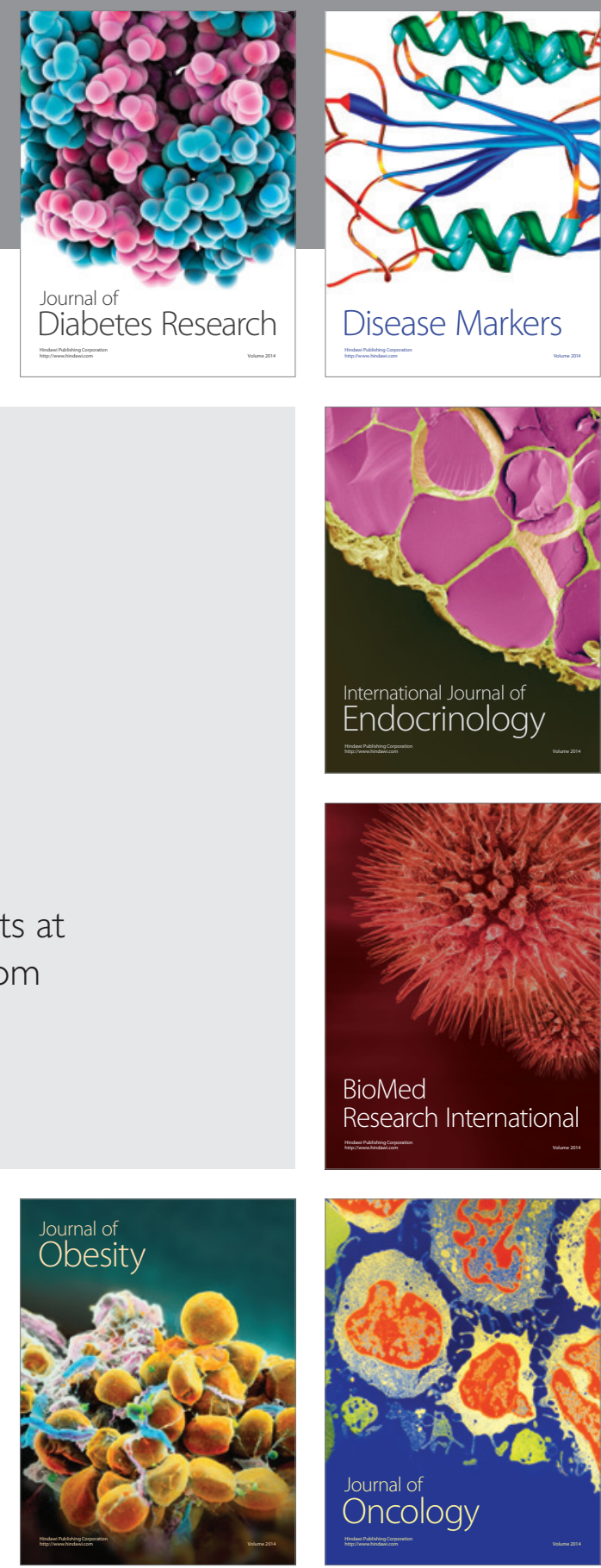

Disease Markers
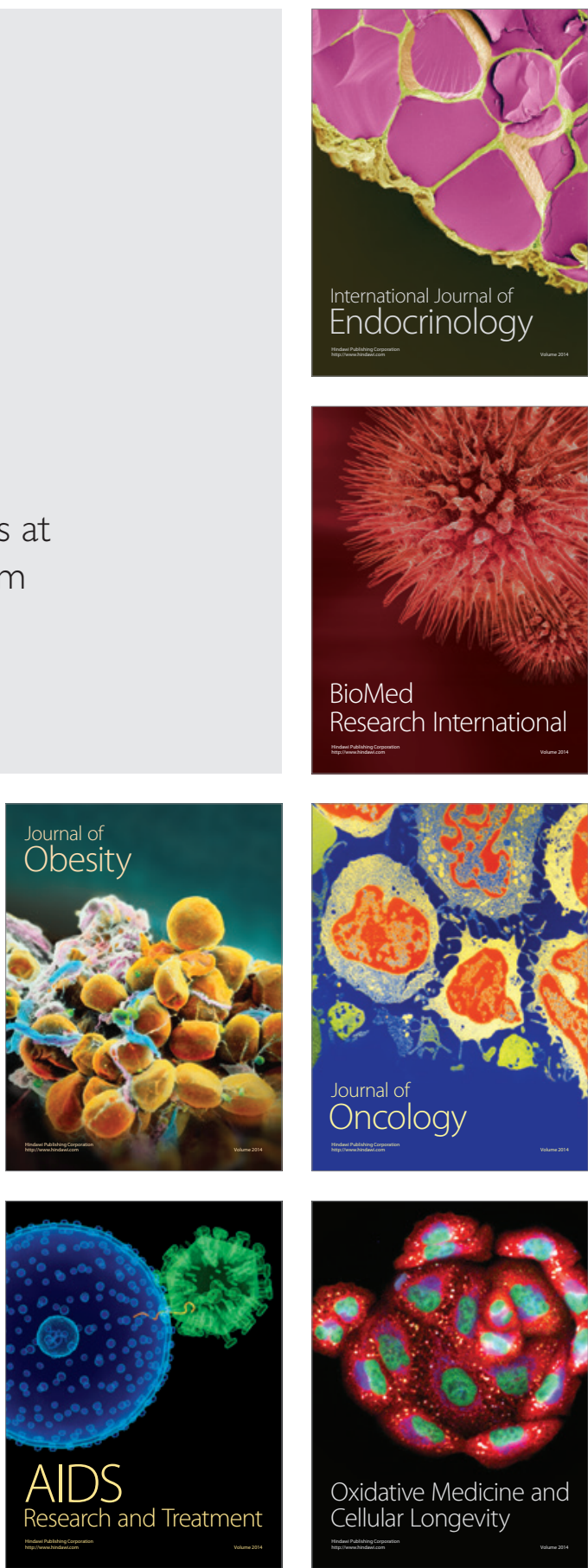